\title{
Implications of low-density microfilariae carriers in Anopheles transmission areas: molecular forms of Anopheles gambiae and Anopheles funestus populations in perspective
}

Bethel Kwansa-Bentum ${ }^{1,2}$, Fred Aboagye-Antwi ${ }^{1,2}$, Joseph Otchere ${ }^{2}$, Michael David Wilson ${ }^{2}$ and Daniel Adjei Boakye ${ }^{2^{*}}$

\begin{abstract}
Background: Previous studies have shown a general reduction in annual transmission potential (ATP) of Anopheles species after mass drug administration (MDA) in lymphatic filariasis endemic communities. Whereas results obtained from a monitoring programme after three years of MDA revealed a decrease in ATP of Anopheles funestus this was not the same for An. gambiae s.s. in Ghana. In this study, the ability of these vectors in transmitting Wuchereria bancrofti in nine lymphatic filariasis endemic communities in Gomoa District of Ghana after four rounds of MDA with ivermectin and albendazole was investigated.

Methods: After mass screening of inhabitants in these communities, twelve consenting volunteers with different intensities of microfilariae ( $\mathrm{mf}$ ) slept under partly opened mosquito nets as sources of $\mathrm{mf}$ blood meal. Hourly collection of mosquitoes and finger-pricked blood were taken from 21.00 to 06.00 hours the following day. For each hour, half of the mosquitoes collected were immediately killed and dissected for $\mathrm{mf}$. The remaining half were maintained up to 13 days for parasite maturation. Parasitaemia and infection rates in the mosquitoes were determined by microscopy. The mosquitoes were identified by microscopy and molecular techniques.

Results: A total of 1,083 participants were screened and the overall parasite prevalence was $1.6 \%$ with $\mathrm{mf}$ intensities ranging from 0 to 59 per $100 \mu \mathrm{l}$ and geometric mean intensity of $1.1 \mathrm{mf}$ per $\mathrm{ml}$ of blood. Of the 564 mosquitoes collected, 350 (62.1\%) were Anopheles spp., from which 310 (88.6\%) were An. funestus and 32 (9.1\%) An. gambiae. Six anopheline mosquitoes (1.7\%) were found infected with $L_{1}$, but no larva was observed in any of the mosquitoes maintained up to 13 days. Molecular studies showed all An. gambiae s.l. to be An. gambiae s.s., of which 21 (70\%) were of the M molecular form.
\end{abstract}

Conclusion: At low-level parasitaemia after 4 rounds of MDA, there was no recovery of infective stage larvae of W. bancrofti in An. funestus s.l. as well as $\mathrm{M}$ and $\mathrm{S}$ forms of An. gambiae.

Keywords: Mass drug administration, Low-density microfilariae carriers, Wuchereria bancrofti, Anopheles gambiae, Anopheles funestus

\footnotetext{
* Correspondence: dboakye@noguchi.ug.edu.gh

2Parasitology Department, Noguchi Memorial Institute for Medical Research,

P.O. Box LG 581 Legon, Accra, Ghana

Full list of author information is available at the end of the article
} 


\section{Background}

Wuchereria bancrofti is one of the three filarial worms responsible for about $90 \%$ of all lymphatic filariasis (LF) cases in the world [1]. These parasites are transmitted through the bite of infective mosquitoes of various genera. A competent vector is one that is capable of ingesting microfilariae ( $\mathrm{mf}$ ) from an infected human, supporting their development to the infective stage larvae $\left(\mathrm{L}_{3}\right)$ and subsequently transmitting them to other uninfected persons. Depending on the vector species, its region of origin and the parasite density ingested, this ability to sustain the maturation and transmission of LF may be enhanced or restricted $[2,3]$. Low density $\mathrm{mf}$ is defined as the density of circulating $\mathrm{mf}$ in a specified blood compartment that cannot be detected in a significant number of instances when commonly used blood sampling techniques are applied in epidemiological studies; thus $4 \mathrm{mf}$ per $20 \mu \mathrm{l}$ (200 mf per $\mathrm{ml}$ ) [4]. Zhang et al. [5] in their study reported that between 1.55 and $2.23 \%$ prevalence, there was a threshold provided no individual had an mf density of more than 12 mf per $60 \mu$ of blood.

The Global Programme to Eliminate Lymphatic Filariasis (GPELF) was launched in 2000, with the main goal of halting transmission and reducing disability through annual mass drug administration (MDA) to all persons at risk of infection, particularly if the vectors are Anopheles species [6]. The strategy relies on the assumption that if the mf reservoir in the human host is reduced below a certain threshold, transmission of $W$. bancrofti by anopheline vectors could be interrupted [7]. This is due to the observation that even though Anopheles mosquitoes yield more infective stage larvae than Culex species, the latter is more efficient at ingesting and developing low-density $\mathrm{mf}$ (limitation) than the former [4]. Thus Anopheles mosquitoes are presumed to be efficient vectors of LF when the parasite density in the human population is high, a phenomenon known as "facilitation" [4]. This observation has been the source for the heightened interest in the advocacy for the possible elimination of anopheline-transmitted filariasis; however, a study has observed "facilitation" in An. gambiae s.s. and An. arabiensis but not in An. melas in Gambia or An. merus in Tanzania [4]. Additional health benefits of MDA targeting LF is the reduction in soil transmitted helminths and scabies [8].

A study in the Bongo district of northern Ghana [9] indicates a plausible "limitation" in An. gambiae s.l. and/or $A n$. funestus in the transmission of the parasite contrary to other reports [4]. Results from a study in the Gomoa district of southern Ghana also indicated that although transmission potential by An. funestus has decreased significantly after mass chemotherapy with ivermectin and albendazole, there appears to be no change in An. gambiae s.s. in the area (Boakye DA, unpublished data). This suggests that probably not all anophelines exhibit facilitation in their transmission of LF. This work was therefore conducted to determine the roles of these two Anopheles species in the transmission of low level $W$. bancrofti human $\mathrm{mf}$, since this information is fundamental to the success of GPELF.

\section{Methods \\ Study sites}

Nine LF endemic communities in the Gomoa district of Ghana (between Latitude $5^{\circ} 24^{\prime}-35^{\prime} \mathrm{N}$ and Longitude $0^{\circ}$ $\left.25^{\prime}-36^{\prime} \mathrm{W}\right)$ were selected based on available data on the disease epidemiology in the population and vector species distribution [10-12]. These are Amanful, Ayesuano, Dago, Fawomanye, Hwida, Kyiren, Mampong, Obiri and Okyereko. The district lies in the coastal savannah zone of Ghana and is located $50 \mathrm{~km}$ west of Accra, the capital city of Ghana. Average annual rainfall ranges between 760 and $1000 \mathrm{~mm}$, whilst mean annual temperature ranges between 26 and $30^{\circ} \mathrm{C}$. The main occupations of the inhabitants are farming and fishing for those living near the shores of the Atlantic Ocean.

\section{Mass screening for microfilariae in the communities}

This study was conducted from April to June 2004, the fourth year of MDA with ivermectin and albendazole in these communities. The areas also form part of an on-going annual longitudinal community-based intervention study. Human participation and the mosquito collection were done by cluster sampling method. Mass screening of the study population for $\mathrm{mf}$ was done by collecting $100 \mu \mathrm{l}$ finger-pricked blood from each individual into heparinised capillary tubes and immediately mixing with $900 \mu \mathrm{l} 3 \%$ acetic acid. Quantification of parasitaemia used the Sedgwick-Rafter counting chamber method with the compound microscope set at $\times 100$ magnification [13].

\section{Mosquito collection, maintenance and dissection}

After consenting to participate, twelve adult volunteers with varying $\mathrm{mf}$ levels slept under partially opened mosquito nets hung over beds in their rooms. At the mid-point of each collection hour, finger-pricked blood was taken and $\mathrm{mf}$ density estimated using the same procedure described above. Mosquitoes trapped in the nets were collected each hour from 21.00 hours to 06.00 hours on the next day using an aspirator. About half the number of mosquitoes collected were killed immediately and dissected for ingested $\mathrm{mf}$. The remaining mosquitoes were fed on $10 \%$ sugar solution and maintained for up to 13 days in paper-cups at $26-28 \times \mathrm{C}$, relative humidity $70-80 \%$ and 12-hour photoperiod in the insectary [14]. Mosquitoes that died before day 13 were dissected for developing stages of $W$. bancrofti, whilst those that survived until the last day were dissected for the presence of infective stage $\mathrm{L}_{3}$ larvae of the parasite. 


\section{PCR identification of Anopheles species}

Molecular identifications of An. gambiae, An. funestus and $W$. bancrofti were conducted using already established methods [15-17]. For the vector species identification, genomic DNA was extracted from the carcasses of mosquitoes after homogenisation with sterile Konte's plastic pestles in $100 \mu \mathrm{l}$ bender buffer. The homogenate was then incubated at $65^{\circ} \mathrm{C}$ for $30 \mathrm{~min}$, followed by the addition of $125 \mu \mathrm{l}$ of phenol. The Centrifuge $5415 \mathrm{C}$ (Eppendorf) was used in all spinning of samples, unless otherwise stated. The mixture was vortexed and spun at 14,000 rpm for $10 \mathrm{~min}$. The supernatant was transferred into a fresh tube and $250 \mu \mathrm{l}$ of pre-chilled absolute ethanol and $10 \mu \mathrm{l}$ of $8 \mathrm{M}$ potassium acetate were added. This was incubated at $-40^{\circ} \mathrm{C}$ for an hour, spun at 10,000 rpm for $10 \mathrm{~min}$ and supernatant poured off. The pellet was then rinsed with $200 \mu$ of $70 \%$ ethanol, spun at 10,000 rpm for $5 \mathrm{~min}$, and supernatant poured off. The pellet was dried and re-dissolved in $50 \mu \mathrm{l}$ $\mathrm{TE}+\mathrm{RNAse}$ and then kept at $4^{\circ} \mathrm{C}$ until ready for PCR (Table 1). Each PCR reaction mixture of $25 \mu \mathrm{l}$ contained $1 \times$ PCR buffer (Sigma, USA), $200 \mu \mathrm{M}$ each of the four deoxyribonucleotide triphosphates, $10 \mu \mathrm{M}$ each of the oligonucleotide primers (Table 1), and 0.125 units of Taq Polymerase enzyme (Sigma, USA). A microliter of the genomic DNA was used as template for the amplification reaction. Anopheles gambiae s.s. were further identified and differentiated into the $\mathrm{M}$ and $\mathrm{S}$ molecular forms by enzymatic restriction of the PCR product as described by Fanello et al. [18]. This was done by amplification of $1.3 \mathrm{~kb}$ rDNA followed by restriction fragment length polymorphism (RFLP) with restriction enzyme Hha I (Sigma-Aldrich, USA).
After gene amplification and digestion, the PCR products were electrophoresed separately in $2 \%$ agarose gel. The gel was prepared by adding TAE buffer to the powder, which was placed in a microwave oven $(230 \mathrm{~V}, 50 \mathrm{~Hz}$, $2660 \mathrm{~W}, 12.0 \mathrm{~A}$ ) for 1 minute to dissolve the solute, and then stained with $0.5 \mu \mathrm{g} / \mathrm{ml}$ Ethidium Bromide. For the electrophoresis, $8 \mu \mathrm{l}$ of each sample was added to $1 \mu \mathrm{l}$ of orange $\mathrm{G}(5 \mathrm{X})$ gel loading dye after placing the solidified gel in 1X TAE buffer in a mini gel system (BIORAD USA). One hundred volts of electric current was passed through it for an hour and the gel photographed over a UV transilluminator (UPC, USA) at short wavelength using a Polaroid camera and film type 667 (Polaroid, USA). The sizes of the PCR products were estimated by comparison with the mobility of a 100 base pair molecular weight size marker (Sigma).

\section{Molecular identification of Wuchereria bancrofti larvae in mosquito vectors}

After the carcass of infected mosquito was scrapped into $1.5 \mathrm{ml}$ eppendorf tubes, DNeasy Tissue Kit (QIAGEN Inc., USA) was used in the extraction of the parasite's genomic DNA from animal tissues following the manufacturer's recommended protocol. After the DNA extraction, aliquots of $5 \mu \mathrm{l}$ of the filarial DNA extract from the mosquitoes were used as templates for the amplification reaction. The PCR assay was performed using two published specific oligonucleotide primers, NV-1 and NV-2 [17]. The PCR products were electrophoresed in $2 \%$ agarose gel as described in the previous section.

Table 1 Oligonucleotide primer sequences and PCR reaction conditions for species identification

\begin{tabular}{|c|c|c|c|}
\hline Primer for species ID & Sequence $5^{\prime} \Rightarrow 3^{\prime}$ & PCR product size (bp) & PCR conditions \\
\hline \multicolumn{4}{|c|}{ Anopheles gambiae s.l. species } \\
\hline Universal primer & GTGTGCCCCTTCCTCGATGT & 468 & \multirow{5}{*}{$\begin{array}{l}93^{\circ} \mathrm{C} 3^{\prime} \text { followed by } 35 \text { cycles }\left(93^{\circ} \mathrm{C} 30^{\prime \prime} ; 50^{\circ} \mathrm{C} 30^{\prime \prime} ; 72^{\circ} \mathrm{C} 1^{\prime}\right) \\
93^{\circ} \mathrm{C} 30^{\prime \prime} ; 50^{\circ} \mathrm{C} 30^{\prime \prime} ; 72^{\circ} \mathrm{C} 10^{\prime}\end{array}$} \\
\hline Anopheles gambiae s.s. & CTGGTTTGGTCGGCACGTIT & 390 & \\
\hline Anopheles merus/melax & TGACCAACCCACTCCCTTGA & 464 & \\
\hline Anopheles arabiensis & AAGTGTCCTTCTCCATCCTA & 315 & \\
\hline Anopheles quadrianulatus & CAGACCAAGATGGTTAGTAT & 153 & \\
\hline \multicolumn{4}{|c|}{ Anopheles funestus s.l. species } \\
\hline Universal primer & TGTGAACTGCAGGACACAT & & \multirow[t]{6}{*}{30 cycles $\left(94^{\circ} \mathrm{C} 30^{\prime \prime} ; 40^{\circ} \mathrm{C} 30^{\prime \prime} ; 72^{\circ} \mathrm{C} 30^{\prime \prime}\right) ; 72^{\circ} \mathrm{C} 10^{\prime}$} \\
\hline Anopheles funestus s.s. & GCATCGATGGGTTAATCATG & 460 & \\
\hline Anopheles vaneedeni & TGTCGACTTGGTAGCCGAAC & 555 & \\
\hline Anopheles rivulorum & CAAGCCGTTCGACCCTGATT & 400 & \\
\hline Anopheles parensis & TGCGGTCCCAAGCTAGGTTC & 235 & \\
\hline Anopheles leesoni & TACACGGGCGCCATGTAGTT & 146 & \\
\hline \multicolumn{4}{|l|}{ Wuchereria bancrofti } \\
\hline$N V-1$ & CGTGATGGCATCAAAGTAGCG & 188 & \multirow{2}{*}{$\begin{array}{l}94^{\circ} \mathrm{C} 3^{\prime} ; \text { followed by } 35 \text { cycles }\left(94^{\circ} \mathrm{C} 1^{\prime} ; 55^{\circ} \mathrm{C} 1^{\prime} ; 72^{\circ} \mathrm{C} 2^{\prime}\right) \text {; } \\
94^{\circ} \mathrm{C} 1^{\prime} ; 55^{\circ} \mathrm{C} 1^{\prime} ; 72^{\circ} \mathrm{C} 10^{\prime \prime}\end{array}$} \\
\hline$N V-2$ & СCCTCACTTACCATAAGACAAC & 188 & \\
\hline
\end{tabular}


Table 2 Prevalence of $\mathrm{mf}$ and the geometric mean intensity in the study area

\begin{tabular}{|c|c|c|c|c|c|c|c|c|c|c|}
\hline \multirow{2}{*}{$\begin{array}{l}\text { Age } \\
\text { group (yrs) }\end{array}$} & \multicolumn{3}{|c|}{ Individuals examined } & \multicolumn{3}{|c|}{ mf positive individual (\%) } & \multicolumn{4}{|c|}{ *mf geometric mean intensity } \\
\hline & Female & Male & Total & Female & Male & Total & Female & Male & Total & mf positives only \\
\hline $1-14$ & 242 & 252 & 494 & $2(0.36)$ & $3(0.56)$ & $5(0.46)$ & 1.05 & 1.05 & 1.05 & 127.85 \\
\hline $15-24$ & 114 & 137 & 251 & 0 & $5(0.93)$ & $5(0.46)$ & 0 & 1.18 & 1.05 & 86.40 \\
\hline $25-34$ & 57 & 44 & 101 & 0 & 0 & 0 & 0 & 0 & 0 & 0 \\
\hline $35-44$ & 42 & 30 & 72 & $1(0.18)$ & 0 & $1(0.09)$ & 1.10 & 0 & 1.06 & 51 \\
\hline $45+$ & 92 & 73 & 165 & $3(0.55)$ & $3(0.56)$ & $6(0.55)$ & 1.10 & 1.23 & 1.16 & 53.66 \\
\hline All & 547 & 536 & 1083 & $6(1.10)$ & $11(2.05)$ & $17(1.57)$ & 1.05 & 1.10 & 1.07 & 79.45 \\
\hline
\end{tabular}

*Antilog $[\Sigma \log (x+1) / n]$, where $x$ is the number of $\mathrm{mf}$ per $\mathrm{ml}$ of blood in mf individuals and $\mathrm{n}$ is the number of people examined [9].

\section{Molecular identification of Wuchereria bancrofti microfilariae in human blood}

Microfilariae (mf) in human blood samples that were preserved in 3\% acetic acid were also characterised after extracting the genomic DNA using the same kit described above. Infected blood samples were amplified and identified using the same procedure described in previous sections.

\section{Ethical considerations}

For the yearly MDA and mass screening for mf prevalence in the communities, oral informed consent was sought from all participants. Subsequently, written consent was obtained from each volunteer who slept under bed nets after the study purpose, procedures, entry and exit criteria were explained to them. All volunteers and the entire community members received that year's round of MDA immediately after the blood sample collection. The Institutional Review Board of Noguchi Memorial Institute for Medical Research approved the study.

\section{Statistical analysis}

Data were entered into Microsoft Access and analysed for the vector competency of Anopheles spp. in supporting the development of $\mathrm{mf}$ to the infective stage larvae. The same software was used to calculate the geometric mean intensity on $\mathrm{mf}$ in the human population. One-way analysis of variance (ANOVA) was used to test for the significance of age- and gender-specific variations between the human population and $\mathrm{mf}$, with $p$ value set at 0.05 .

\section{Results}

Human microfilariae load in the communities after four rounds of MDA

The overall prevalence of $\mathrm{mf}$ in the study communities $(N=1083)$ was $1.6 \%$; mf prevalence among males and females $(2.05 \%$ and $1.10 \%$ respectively) was not significantly different $(p=0.39)$. The $\mathrm{mf}$ levels ranged from 0 to $59 /$ $100 \mu \mathrm{l}$ blood with geometric mean intensity of $1.1 \mathrm{mf} / \mathrm{ml}$ of blood (Table 2). There was no significant variation in $\mathrm{mf}$ intensity and age-group $(p=0.40)$; likewise no significant difference between $\mathrm{mf}$ intensity and gender of participants $(p=0.91)$ (Table 2). Four out of the nine communities namely Ayesuano, Dago, Hwida and Okyereko recorded positive cases, with Okyereko having the highest number of cases (Table 3). Among the positive cases, Okyereko recorded $155.6 \mathrm{mf} / \mathrm{ml}$ of blood whilst Dago recorded 15.3 $\mathrm{mf} / \mathrm{ml}$ of blood.

Mosquito species composition and entomological indices The 564 mosquitoes collected consisted of 350 (62.1\%) Anopheles, 182 (32.3\%) Mansonia, 28 (5\%) Aedes and 4 (0.7\%) Culex species, (Figure 1). The Anopheles species comprised of 310 (88.6\%) An. funestus, 32 (9.1\%) An. gambiae and 8 (2.3\%) An. Pharoensis, (Figure 1). The hourly biting rates of An. gambiae and An. funestus were 6.4 and 62 bites/person/night respectively (Table 4). Of the mosquito species collected, 192 (34\%) were engorged with bloodmeals (Table 5). Whereas 6/350 (1.7\%) of the Anopheles and 6/182 (3.3\%) of the Mansonia species were found with the $\mathrm{mf}\left(\mathrm{L}_{1}\right.$ stage) of $W$. bancrofti, there was no recovery of $\mathrm{L}_{3}$ or $\mathrm{L}_{2}$ stage larvae after 12 days of maintenance. While each of the infected An. gambiae had an average of one mf, each $A n$. funestus had an average of eight $\mathrm{mf}$ when killed immediately after collection (Table 5). The mf load in the peripheral blood and biting rates of Anopheles mosquitoes peaked concurrently between 0.30 and 2.30 hours (Figure 2).

Table 3 Blood sampling results showing number of people infected with microfilaria of Wuchereria bancrofti in the year 2004 (four years of MDA)

\begin{tabular}{lccc}
\hline $\begin{array}{l}\text { Study } \\
\text { communities }\end{array}$ & $\begin{array}{c}\text { Number } \\
\text { examined }\end{array}$ & $\begin{array}{c}\text { Number positive } \\
\text { (mf density/ml of blood) }\end{array}$ & $\begin{array}{c}\text { Geometric mean } \\
\text { intensity (mf/ml) }\end{array}$ \\
\hline Amanful & 61 & 0 & 0 \\
Ayesuano & 69 & $1(4)$ & 1.0 \\
Dago & 228 & $4(1-15.3)$ & 1.0 \\
Fawomanyo & 66 & 0 & 0 \\
Hwida & 88 & $2(5-21)$ & 1.0 \\
Kyiren & 161 & 0 & 0 \\
Mampong & 63 & 0 & 0 \\
Obiri & 70 & 0 & 0 \\
Okyereko & 277 & $10(1-155.6)$ & 1.2 \\
\hline
\end{tabular}




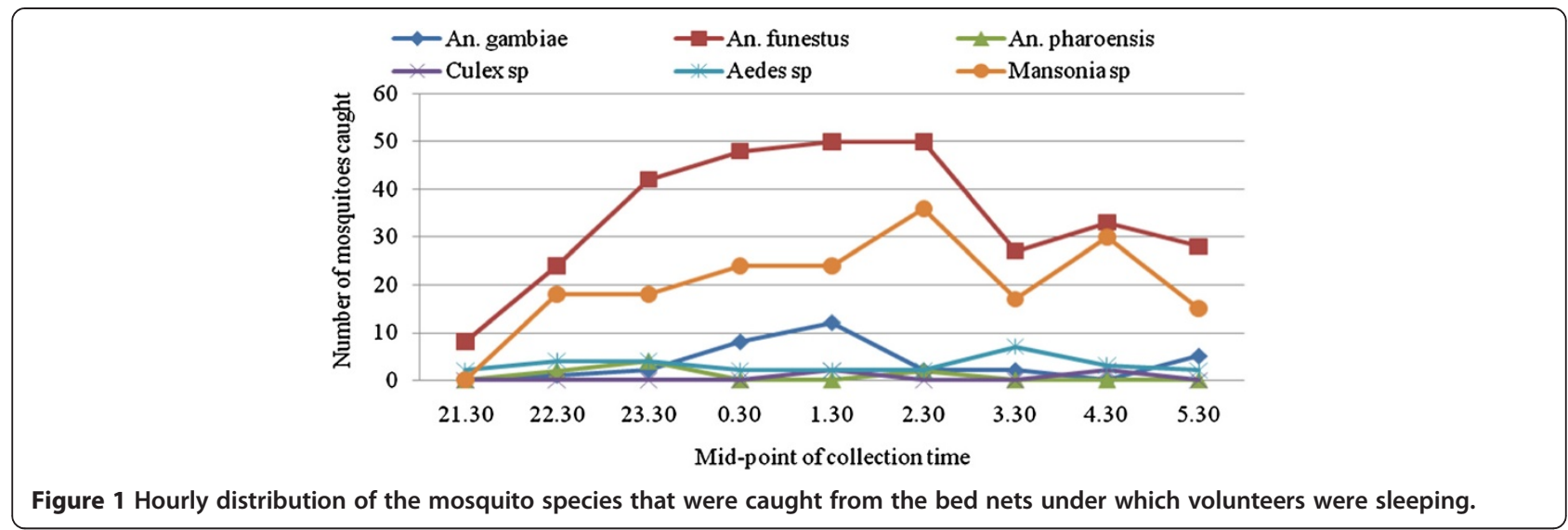

\section{PCR identification of Anopheles mosquitoes and Wuchereria bancrofti}

Of the 32 An. gambiae s.l. collected, 30 were identified as An. gambiae s.s. as they showed the expected diagnostic band size of 390 base pairs. After restriction enzyme treatment with Hha I, M forms remained a single band of 390 bp since there was no digestion. $\mathrm{S}$ forms on the other hand resulted in two bands of 110 and $280 \mathrm{bp}$. Of the $A n$. gambiae s.s digested, 21 (70\%) were M forms with 9 (30\%) $\mathrm{S}$ molecular forms. Among the 310 An. funestus s.l. collected, 286 were identified by PCR; of which 267 (86\%) were An. funestus s.s. with diagnostic band sizes of 460 base pairs, and 19 (6\%) were An. Leesoni with band sizes of 146 base pairs. The presence of W. bancrofti in 20 infected mosquitoes and 10 human blood samples were confirmed at $188 \mathrm{bp}$.

\section{Discussion}

An LF-endemic community is said to have low $\mathrm{mf}$ density when the density of circulating $\mathrm{mf}$ is less than $200 \mathrm{mf}$ per $\mathrm{ml}$ of blood, an amount which cannot be detected in a significant number of instances when commonly used blood sampling techniques are employed [4]. Nonetheless, this depends on variables such as volume of blood examined, source of blood sampled (venous or capillary) and method of $\mathrm{mf}$ detection that is employed. In this study, $100 \mu \mathrm{l}$ of finger-prick blood was used, which is an appreciable amount of blood compared to the popular technique for $\mathrm{mf}$ detection in routine public health practice of $20 \mu \mathrm{l}$ finger-prick blood [4]. As such it could be inferred that the mean mf intensity of 1.07 and $79.45 \mathrm{mf}$ per $\mathrm{ml}$ of capillary blood in the entire study communities and $\mathrm{mf}$ positive individuals respectively were really low in the studied area. This may be due to the $66.6 \%$ overall coverage rate in MDA with ivermectin and albendazole for 4 years leading to a reduction in $\mathrm{mf}$ densities among the inhabitants (Boakye DA, unpublished data). Evidence from Okyereko supports this view that MDA has been effective; in this study period, $155.6 \mathrm{mf}$ per $\mathrm{ml}$ of blood were recorded among $\mathrm{mf}$ positive individuals, hitherto the commencement of MDA, as high as $819 \mathrm{mf} / \mathrm{ml}$ of blood were recorded among this group [12].

Various observations have been made regarding $\mathrm{mf}$ prevalence and intensities in study populations $[9,11,12,22]$. These could be attributed in part to the occupational activities of inhabitants of the study areas as well as the biting pattern of the local anopheline vectors, which are presently known to be the main vectors of LF in Ghana [10-12]. Studies on the relationship between mf density in blood meals and the percentage of Anopheles mosquitoes that

Table 4 Entomological indices of the various mosquito species that were caught during the study

\begin{tabular}{|c|c|c|c|c|c|c|}
\hline \multirow{2}{*}{$\begin{array}{l}\text { Mosquito } \\
\text { species }\end{array}$} & \multicolumn{6}{|c|}{ Entomological indices (\%) } \\
\hline & Biting rate $^{a}$ & Infection rate ${ }^{b}$ & Infectivity rate ${ }^{c}$ & Intensity of infection ${ }^{d}$ & Survival rate & Vector efficiency $^{f}$ \\
\hline An. gambiae & 6.4 & 0.13 & 0 & 0 & 0.50 & 0 \\
\hline An. funestus & 62.0 & 0.03 & 0 & 0 & 0.47 & 0 \\
\hline An. pharoensis & 1.6 & 0 & 0 & 0 & 1.0 & 0 \\
\hline Culex sp & 0.8 & 0 & 0 & 0 & 0 & 0 \\
\hline Aedes sp & 5.6 & 0 & 0 & 0 & 5.0 & 0 \\
\hline Mansonia sp & 36.4 & 0.07 & 0 & 0 & 0.12 & 0 \\
\hline
\end{tabular}

${ }^{a}$ Number of mosquitoes caught/ number of collectors $x$ number of captures (bites/ person/ night); ${ }^{b}$ Number of mosquitoes infected/ number of mosquitoes dissected; ${ }^{C} L_{3}$ in the head and proboscis/ number of surviving mosquitoes; ${ }^{d}$ Number of mosquitoes with $L_{3}$ in the head and proboscis/ number of mosquitoes

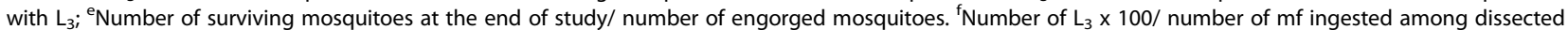
mosquitoes [19-21]. 
Table 5 Number of mosquitoes caught and examined before and after maintenance in the laboratory

\begin{tabular}{|c|c|c|c|c|c|c|c|c|}
\hline \multirow[t]{2}{*}{$\begin{array}{l}\text { Mosquito } \\
\text { species }\end{array}$} & \multicolumn{2}{|c|}{ No: of mosquitoes } & \multicolumn{2}{|c|}{$\begin{array}{l}\text { No: of mosquitoes } \\
\text { examined immediately } \\
\text { after collection }\end{array}$} & \multicolumn{2}{|c|}{$\begin{array}{l}\text { No: of mosquitoes } \\
\text { examined from days } \\
1-8 \text { of maintenance }\end{array}$} & \multicolumn{2}{|c|}{$\begin{array}{l}\text { No: of mosquitoes } \\
\text { examined from days } \\
9-13 \text { of maintenance }\end{array}$} \\
\hline & Caught & Engorged with blood & Dissected & Infected (no: $\mathrm{mf}$ ) & Dissected & Infected (no: $\mathrm{mf}$ ) & Dissected & Infected \\
\hline An. gambiae & 32 & 12 & 16 & $2(2)$ & 10 & $2(3)$ & 6 & 0 \\
\hline An. funestus & 310 & 98 & 155 & $4(33)$ & 109 & $4(4)$ & 46 & 0 \\
\hline An. pharoensis & 8 & 2 & 4 & $0(0)$ & 2 & 0 & 2 & 0 \\
\hline Culex sp. & 4 & 2 & 2 & $0(0)$ & 2 & 0 & 0 & 0 \\
\hline Aedes sp. & 28 & 2 & 14 & $0(0)$ & 4 & 0 & 10 & 0 \\
\hline Mansonia sp. & 182 & 76 & 90 & $6(12)$ & 82 & $7(7)$ & 9 & 0 \\
\hline Total & 564 & 192 & 281 & $12(47)$ & 209 & $13(14)$ & 73 & 0 \\
\hline
\end{tabular}

All $\mathrm{mf}$ found in mosquitoes were of $\mathrm{L}_{1}$ stage, neither $\mathrm{L}_{2}$ nor $\mathrm{L}_{3}$ stages were found. All mosquitoes caught were dissected latest by end of the maintenance (13 days).

ingest $\mathrm{mf}$ have not provided consistent results [3,9,22-25]. Southgate and Bryan [26] showed that although many of the $\mathrm{mf}$ ingested by Anopheles vectors are damaged by the mosquito's foregut armature, the proportion of $\mathrm{mf}$ destroyed does not depend on the number of $\mathrm{mf}$ ingested and varies between members of the $A n$. gambiae complex and An. funestus. It is therefore not proper to extend findings from a given area to the other even for the same species. Additionally, other anatomical structures and immune factors other than the foregut armature could be modulating $\mathrm{mf}$ density following ingestion. Further studies are thus required to provide more understanding into the vector-parasite relationships.

Indeed the significance of distinctly different hostparasite relationships lies in the importance of low-density $\mathrm{mf}$ in sustaining transmission in various endemic areas with different genera of mosquito vectors [4]. As hypothesised, the theory of "limitation" allows transmission to occur and build-up when most infected human hosts have low mf densities, whereas situations of well marked "facilitation" will give rise to transmission thresholds below which transmission will ultimately cease leading to parasite elimination from the human population. However, such predictions of parasite extinction or parasite resurgence can only be made with confidence when characteristics of the local vector-mf relationship are well understood [7].

As part of our study, we described the circadian pattern of $\mathrm{mf}$ periodicity in southern Ghana. Based on hourly examination of twelve volunteers for nine hours, we observed that $\mathrm{mf}$ concentration in peripheral blood followed a wave-like concentration peaking around 01.00 hours, which was similar to other findings $[12,27,28]$. This interesting behavioural pattern of $\mathrm{mf}$ is said to be the parasite's response to oxygen tension, which is high in peripheral circulation at night due to the low human activity at this time of the day $[29,30]$.

In their study, Dzodzomenyo M. et al. [12] observed $A n$. funestus to be the most abundant mosquito species in the early dry season while An. gambiae was predominant in the wet season. Our study was conducted in March, which is the peak of the dry season in Ghana and thus may contribute to the low number of $A n$. gambiae that were

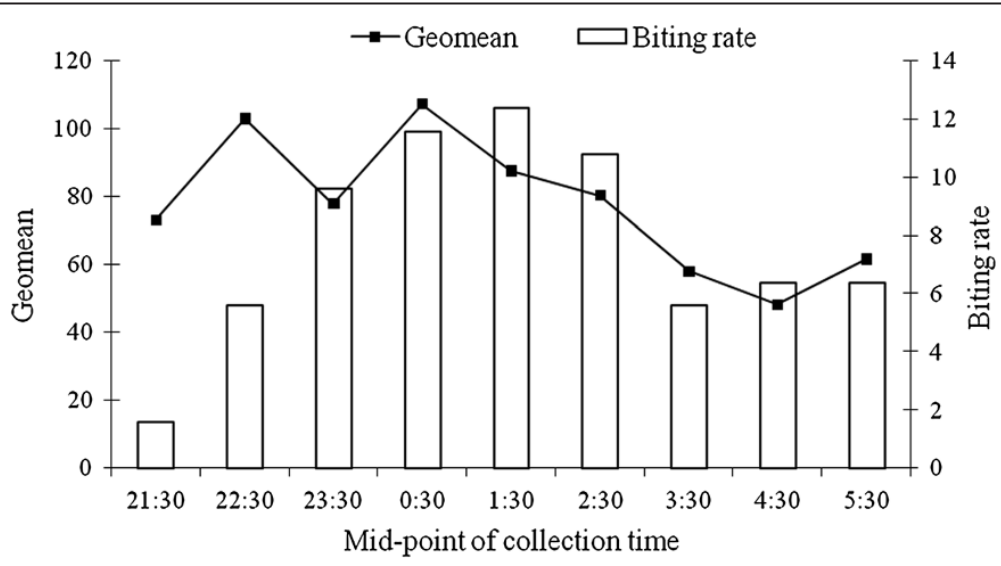

Figure 2 Biting rate of Anopheles species and the geometric mean intensity (Geomean) of mf that were observed during the night of sample collection. 
captured. Studies show that the M and S forms of Anopheles gambiae s.s. do occur in sympatry in southern Ghana [31]. Our study revealed that most of the Anopheles gambiae s.s. were $\mathrm{M}$ form, which has a remarkable ecological flexibility and is known to prevail in inundated areas where dry season breeding opportunities exist [10]. Further studies could look at the role of these molecular forms of Anopheles gambiae s.s. in transmission of W. bancrofti following MDA.

\section{Conclusion}

After 4 rounds of mass drug administration, parasitaemia was brought to a low level in the study communities. Low levels of circulating microfilariae in the inhabitants might have contributed to the no recovery of infective stage larvae of W. bancrofti in An. funestus s.l. as well as M and S forms of An. gambiae. Although the mosquito numbers were low, a further study is recommended to ascertain this observation.

\section{Competing interest}

The authors declare that they have no competing interests.

\section{Authors' contributions}

All authors contributed significantly to this study. DAB and MDW conceived the idea and design of the study. BKB, FAA and JO carried out the field and laboratory studies. BKB prepared the manuscript, while all authors read and approved the final manuscript.

\section{Acknowledgements}

We acknowledge the technical contributions of Sampson Otoo and Philip Doku. We thank the chiefs and elders of the study communities, and all persons who provided blood samples without whom this work would not have seen the light of day. We thank all members of Parasitology Department (NMIMR), and appreciate the support of Professor Alexander Nyarko Director, NMIMR. This work was supported by WHO/ TDR Research Grant to DAB (WHO/TDR grant No. A00638).

\section{Author details}

${ }^{1}$ Department of Animal Biology and Conservation Science, University of Ghana, P.O. Box LG 67 Legon, Accra, Ghana. Parasitology Department, Noguchi Memorial Institute for Medical Research, P.O. Box LG 581 Legon, Accra, Ghana.

Received: 5 December 2013 Accepted: 27 March 2014 Published: 1 April 2014

\section{References}

1. Michael E, Bundy DA, Grenfell BT: Re-assessing the global prevalence and distribution of lymphatic filariasis. Parasitol 1996, 112:409-428.

2. Crans WJ: Experimental infection of Anopheles gambiae and Culex quinquefasciatus pipiens fatigans with Wuchereria bancrofti in coastal East Africa. J Med Entomol 1973, 10:189-193.

3. McGreevy PB, Kolstrup N, Tao J, McGreevy MM, Marshall TF: Ingestion and development of Wuchereria bancrofti in Culex quinquefasciatus, Anopheles gambiae and Aedes aegypti after feeding on humans with varying densities of microfilariae in Tanzania. Trans $R$ Soc Trop Med Hyg 1982, 76:288-296.

4. Southgate BA: The significance of low density microfilareamia in the transmission of lymphatic filarial parasites. J Trop Med Hyg 1992, 95:79-86.

5. Zhang SQ, Zhang QJ, Cheng F, Wang LL, Pen GP: Threshold of transmission of Brugia malayi by Anopheles sinensis. J Trop Med Hyg 1991, 94:245-250.

6. Yamey G: Global alliance launches plan to eliminate lymphatic filariasis. BMJ 2000, 320:269
7. Webber RH: Eradication of Wuchereria bancrofti through vector control. Trans R Soc Trop Med Hyg 1991, 73:722-724

8. Mohammed KA, Deb RM, Stanton MC, Molyneux DH: Soil transmitted helminths and scabies in Zanzibar, Tanzania following mass drug administration for lymphatic filariasis - a rapid assessment methodology to assess impact. Parasit Vectors 2012, 5:299.

9. Boakye DA, Wilson MD, Appawu MA, Gyapong J: Vector competence for Wuchereria bancrofti of the Anopheles populations in the Bongo District of Ghana. Ann Trop Med Parasitol 2004, 98:501-508.

10. Appawu MA, Baffoe-Wilmot A, Afari EA, Nkrumah FK, Petrarca V: Species composition and inversion polymorphism of the Anopheles gambiae complex in some sites of Ghana, West Africa. Acta Trop 1994, 56:15-23.

11. Dunyo SK, Appawu M, Nkrumah FK, Baffoe-Wilmot A, Pedersen EM, Simonsen PE: Lymphatic filariasis on the coast of Ghana. Trans $R$ Soc Trop Med Hyg 1996, 90:634-638.

12. Dzodzomenyo M, Dunyo SK, Ahorlu CK, Coker WZ, Appawu MA, Pedersen EM, Simonsen PE: Bancroftian filariasis in an irrigated project community in southern Ghana. Trop Med Int Health 1999, 4:13-18.

13. McMahon JE, Marshall TF d C, Vaughan JP, Abaru DE: Bancroftian filariasis: a comparison of microfilariae counting techniques using counting chamber, standard slide and membrane (Nucleopore) filtration. Ann Trop Med Parasitol 1979, 73:457-464.

14. Janousek TE, Lowrie RC Jr: Vector competency of Culex quinquefasciatus (Haitian strain) following infection with Wuchereria bancrofti. Trans R SOC Trop Med Hyg 1989, 83:679-680.

15. Collins FH, Mendez MA, Rasmussen MO, Mehaffey PC, Besansky NJ, Finnerty V: A ribosomal RNA gene probe differentiates member species of the Anopheles gambiae complex. Am J Trop Med Hyg 1987, 37:37-41.

16. Scott JA, Brogdon WG, Collins FH: Identification of single specimens of the Anopheles gambiae complex by the polymerase chain reaction. Am J Trop Med Hyg 1993, 49:520-529.

17. Ramzy RM, Farid HA, Kamal IH, Ghada HI, Zakariah SM, Rifky F, Weil GJ, Williams SA, Gad AM: A polymerase chain reaction-based assay for detection of Wuchereria bancrofti in human blood and Culex pipiens. Trans R Soc Trop Med Hyg 1997, 91:156-160.

18. Fanello C, Santolamazza F, della Torre A: Simultaneous identification of species and molecular forms of the Anapheles gambiae complex by PCRRFLP. Med Vet Entomol 2002, 16:461-464.

19. Brito AC, Williams P, Fontes G, Rocha EMM: A comparison of two Brazilian populations of Culex quinquefasciatus (Say, 1823) from endemic and non-endemic areas to infection with Wuchereria bancrofti (Cobbold, 1877). Mem Inst Oswaldo Cruz 1997, 92:33-36.

20. Kartman L: Suggestions concerning an index of experimental filarial infection in mosquitoes. Am J Trop Med Hyg 1954, 3:329-337.

21. Ramachandran CP: A guide to methods and techniques in Filariasis Investigations. Filar Res Off Inst Med Res, Kuala Lumpur 1970:39pp.

22. Coulibaly YI, Dembele B, Diallo AA, Kristensen S, Konate S, Dolo H, Dicko I, Sangare MB, Keita F, Boatin BA, Traore AK, Nutman TB, Klion AD, Touré YT, Traore SF: Wuchereria bancrofti transmission pattern in southern Mali prior to and following the institution of mass drug administration. Parasit Vectors 2013, 6:247.

23. Bryan JH, McMahon $P$, Barnes A: Factors affecting transmission of Wuchereria bancrofti by anopheline mosquitoes. 3. Uptake and damage to ingested microfilariae by An. gambiae, An. arabiensis, An. merus and An. funestus in East Africa. Trans R Soc Trop Med Hyg 1990, 84:265-268.

24. Bryan $\mathrm{JH}$, Southgate BA: Factors affecting transmission of Wuchereria bancrofti by anopheles mosquitoes. 1. Uptake of microfilariae. Trans $R$ Soc Trop Med Hyg 1988, 82:128-137.

25. Bryan $\mathrm{JH}$, Southgate BA: Factors affecting transmission of Wuchereria bancrofti by anopheles mosquitoes. 2. Damage to ingested microfilariae by mosquito foregut armatures and development of filarial larvae in mosquitoes. Trans R Soc Trop Med Hyg 1988, 82:138-145.

26. Southgate BA, Bryan JH: Factors affecting transmission of Wuchereria bancrofti by anopheline mosquitoes. 4 . Facilitation, limitation, proportionality and their epidemiological significance. Trans $R$ Soc Trop Med Hyg 1992, 86:523-530.

27. Tanaka H: Periodicity of microfilariae of human filariasis analysed by a trigonometric method (Aikat and Das). Jpn J Exp Med 1981, 51:97-103.

28. Gatika SM, Fugimaki Y, Njuguna MN, Gachihi GS, Mbugua JM: The microfilarial periodicity pattern of Wuchereria bancrofti in Kenya. J Trop Med Hyg 1994, 97:60-64. 
29. Hawking F, Pattanayak S, Sharma HL: The periodicity of microfilariae XI. The effect of body temperature and other stimuli upon the cycles of Wuchereria bancrofti, Brugia malayi, B. ceylonensis and Dirofilaria repens. Trans R Soc Trop Med Hyg 1966, 60:496-513.

30. Denham DA, McGreevy PB: Brugian filariasis: epidemiological and experimental studies. Adv Parasitol 1977, 15:243-309.

31. Yawson AE, McCall PJ, Wilson MD, Donnelly MJ: Species abundance and insecticide resistance of Anopheles gambiae in selected areas of Ghana and Burkina Faso. Med Vet Entomol 2004, 18:372-377.

doi:10.1186/1756-3305-7-157

Cite this article as: Kwansa-Bentum et al: Implications of low-density

microfilariae carriers in Anopheles transmission areas: molecular forms of Anopheles gambiae and Anopheles funestus populations in perspective.

Parasites \& Vectors 2014 7:157.

\section{Submit your next manuscript to BioMed Central and take full advantage of:}

- Convenient online submission

- Thorough peer review

- No space constraints or color figure charges

- Immediate publication on acceptance

- Inclusion in PubMed, CAS, Scopus and Google Scholar

- Research which is freely available for redistribution 